\title{
A MULTI-REGIONAL ASSESSMENT OF THE AMERICAN Pika (OChotona PRINCEPS) in NATional PARKS
}

\section{JESSICA A. CASTILLO $\diamond$ CLINTON W. EPPS $\uparrow$ OREGON STATE UNIVERSITY $\prec$ CORVALLIS}

\begin{abstract}
$\uparrow \quad$ ABSTRACT
American pikas are conspicuous and charismatic inhabitants of mountainous regions of the western United States. Due to their sensitivity to high temperatures, they are considered an important early warning indicator species for detecting the ecological effects of climate change. This study addresses the potential threat of climate change to American pikas by assessing current occupancy patterns, modeling current gene flow patterns, and combining these two components to project habitat-specific models of occupancy and connectivity into the future under various climate change scenarios. The preliminary results presented here reflect field work conducted in Grand Teton National Park during the summer of 2010 and 2011. We conducted occupancy surveys, collected non-invasive genetic samples, and conducted preliminary genetic analyses.
\end{abstract}

\section{$\uparrow \quad$ INTRODUCTION}

The American pika (Ochotona princeps) is a small lagomorph distributed throughout the mountainous areas of western North America including Canada and the conterminous United States (Figure 1). American pikas are temperature sensitive and rely on talus and other specialized rocky habitats to behaviorally thermoregulate. Climate change has been implicated in recent local extinctions of pika populations, particularly in the Great Basin (Beever et al. 2010, 2011). Research suggests pikas may be an early warning indicator species for detecting ecological effects of climate change (McDonald and Brown 1992, Hafner 1993, 1994, Beever et al. 2003, Krajick 2004, Morrison and Hik 2007, Erb et al.
2011). As a result, pikas are a focal species for climate change research.

The goal of this multi-regional, multidisciplinary study, involving scientists and researchers from the National Park Service and academic institutions, is to assess the vulnerability of this species to climate change in eight National Parks. The eight parks included in this study represent an elevational gradient as well as the various habitat types utilized by pikas. The three objectives of this study are to: 1) document pika occurrence patterns and predict pika distribution, 2) measure gene flow and model connectivity of pika populations, and 3) project climate change effects on the future distribution, connectivity, and vulnerability of pika populations. Objective one will include all eight parks while objectives two and three will include five of the eight parks. Grand Teton National Park is one of the five parks included in objectives two and three.

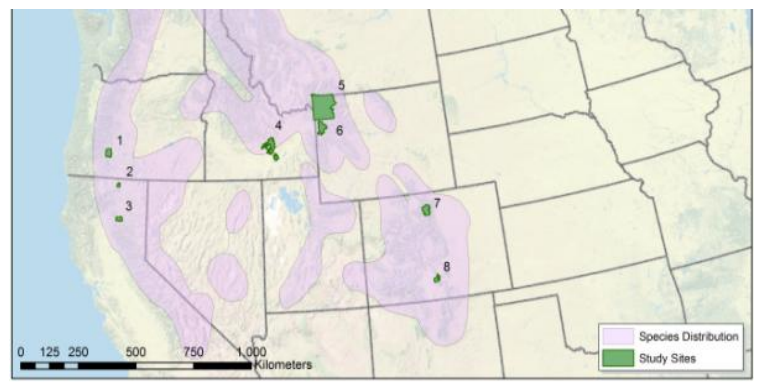

Figure 1. Species distribution and study sites: 1- Crater Lake National Park, 2- Lava Beds National Monument, 3Lassen Volcanic National Park, 4- Craters of the Moon National Monument, 5- Yellowstone National Park, 6Grand Teton National Park, 7- Rocky Mountain National Park, and 8- Great Sand Dunes National Monument. 
The results presented here reflect work done in Grand Teton National Park during the summers of 2010 and 2011 and are preliminary. At the completion of this study, we will identify pika populations that may be a priority for monitoring, provide models of occupancy and genetic diversity to facilitate the evaluation and/or restoration of potential pika habitats and habitat networks, and provide maps of current and hypothesized future pika distribution to facilitate best practices in management of pikas in these parks.

\section{STUDY AREA}

The eight National Parks included in this study are: Crater Lake National Park, Oregon; Lava Beds National Monument, California; Lassen Volcanic National Park, California; Craters of the Moon National Monument, Idaho; Yellowstone National Park, Wyoming, Montana, and Idaho; Grand Teton National Park, Wyoming; Rocky Mountain National Park, Colorado; and Great Sand Dunes National Monument, Colorado (Figure 1). Potential pika habitat varies among the study sites with talus predominating in Grand Teton, Great Sand Dunes, Rocky Mountain, and Yellowstone. Craters of the Moon is characterized by a large series of lava flows, while Lassen and Crater Lake have both talus and lava habitats.

Within Grand Teton National Park, potential pika habitat is restricted to the Teton Range in the western half of the park. Classic talus habitat is typically found on mountain slopes and is composed of creviced rock greater than six inches in diameter that can provide shelter for pikas (Figure 2).

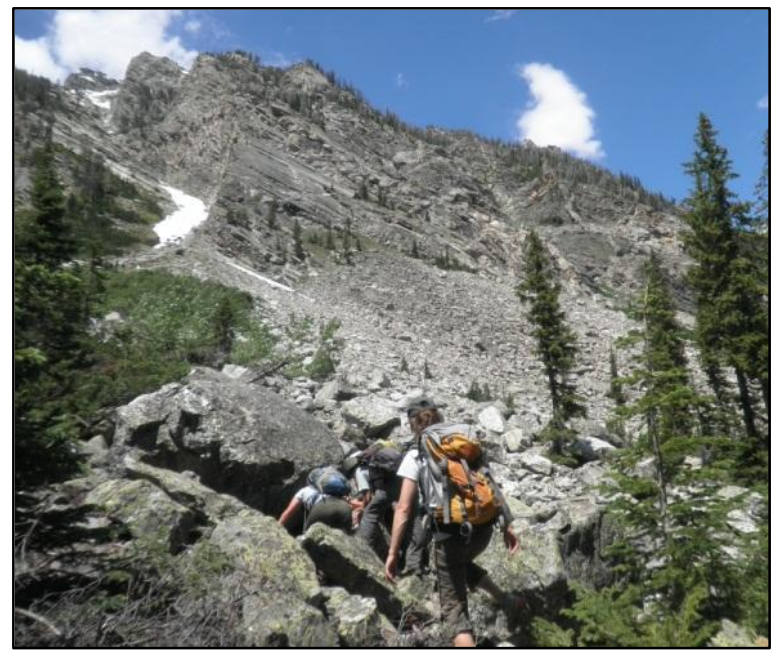

Figure 2. Field crews searching pika habitat at Grand Teton National Park.

\section{$\uparrow \quad$ MeTHODS \\ OCCUPANCY SURVEYS}

Survey site locations were drawn from GISbased models of predicted habitat according to a random stratified design following methods described in the peer-reviewed monitoring protocol developed by the Upper Columbia Basin Network (Jeffress et al. forthcoming 2013). The sampling frame excluded inaccessible areas and those that would require traversing dangerous terrain. For Grand Teton National Park, the sampling frame included areas within $1 \mathrm{~km}$ of roads and $600 \mathrm{~m}$ of maintained trails. Additionally, areas with slope greater than $35^{\circ}$, identified using digital elevation models in a GIS, were designated as hazardous and excluded from the sampling frame. The pika sampling frame was stratified by four elevational quantiles, with spatiallybalanced samples distributed equally across each stratum. Each survey consisted of a systematic search for pika sign as well as characterization of habitat variables including vegetation type and cover.

\section{COLLECTION OF GENETIC SAMPLES}

We obtained genetic material from pika fecal pellets. Non-invasive genetic sampling provides the benefits of enabling collection of a large number of samples without the need to trap individual pikas. Fecal samples were collected according to three sampling schemes: random, from within the occupancy survey plots; opportunistic, while travelling between survey sites; and targeted, while exhaustively searching an area identified as potential habitat. Only the freshest fecal samples available were collected as older, degraded fecal samples will not yield high quality DNA. Fecal samples were handled to avoid contamination with other fecal samples and human DNA. Samples were placed in paper coin envelopes and stored in a cool, dry place.

\section{LAB TECHIQUES}

We conducted lab work in the Epps Population Genetics Laboratory and the Center for Genome Research and Biocomputing (CGRB) at Oregon State University. DNA was extracted from fecal pellets according to a modified AquaGenomic Stool and Soil DNA extraction protocol (MultiTarget Pharmaceuticals LLC, Salt Lake City, UT, USA) presented in Wehausen et al. (2004) and optimized for pika fecal pellets. We amplified a total of 24 microsatellite markers in four polymerase chain reactions using a Qiagen Multiplex PCR kit (Qiagen, Valencia, CA, USA) according to the manufacturer's 
specifications. DNA obtained from fecal pellets is relatively low quality and can result in a high rate of genotyping errors, such as allelic dropout, therefore we genotyped each individual a minimum of three times to ensure accuracy of our data.

\section{$\downarrow \quad$ PRELIMINARY RESULTS}

\section{OCCUPANCY SURVEYS}

Occupancy surveys were carried out if the survey plot, the area within a $12 \mathrm{~m}$ radius of the plot center, contained more than $10 \%$ target habitat. In 2011, seven people conducted occupancy surveys in Grand Teton National Park from 18 July to 28 September. Sixty-seven new sites were surveyed and 37 sites previously surveyed in 2010 were resurveyed in 2011. Fifty of the 104 survey sites were occupied, 31 had only old sign, and 23 lacked any evidence of pika activity within the plot. Therefore, $48 \%$ of the sites surveyed in 2011 were considered currently occupied. Ten of the 37 sites resurveyed changed occupancy status, with three being colonized in 2011 and seven being lost in 2011. This represents 27\% observed site turn over. When the 2010 and 2011 results are combined, 89 of 184 sites (48\%) were considered occupied.

\section{Collection of Genetic Samples}

Fecal samples were collected at Grand Teton National Park during the same time period as occupancy surveys. In 2011, a total of 270 fecal samples were collected. Of those, 189 were collected in association with an occupancy survey. A total of 383 fecal samples were collected at Grand Teton National Park between 2010 and 2011 (Figure 3).

\section{Lab Techniques}

Of the 383 fecal samples collected at Grand Teton National Park, DNA has been extracted from 280. Fecal samples, while relatively easily collected in the field, are more difficult to work with in the lab because prolonged exposure to moisture, variable temperatures, and sunlight degrade the DNA. We have successfully genotyped 228 individuals, representing an $81 \%$ success rate of our fecal DNA extractions.

Another common obstacle encountered with fecal DNA is contamination with other pika DNA. There are four main sources of pika to pika DNA contamination. The first two are related to the behavior of American pikas. Like other lagomorphs, pikas are coprophageous and ingest their own feces as well as the feces of other pikas. This behavior could potentially lead to the DNA from one pika ending up in the feces of another pika. A second behavior of pikas that may lead to contamination is the use of latrines. Pikas are highly territorial and territories are re-used by subsequent individuals. Pikas defecate in huge piles, or latrines, that contain the feces of multiple individuals (Figure 4). If fecal pellets from one individual are touching pellets from another individual, then DNA may be transferred from one pellet to another via physical contact. The remaining two sources of contamination are the result of human error either in the field while collecting pellets, or in the laboratory while processing samples. If a sample is contaminated, it is very difficult to determine the specific source of contamination because there are so many potential sources. Regardless, contaminated samples must be excluded from all analyses. Of the 228 individuals successfully genotyped, 20 were contaminated representing less than $9 \%$ of the samples processed.

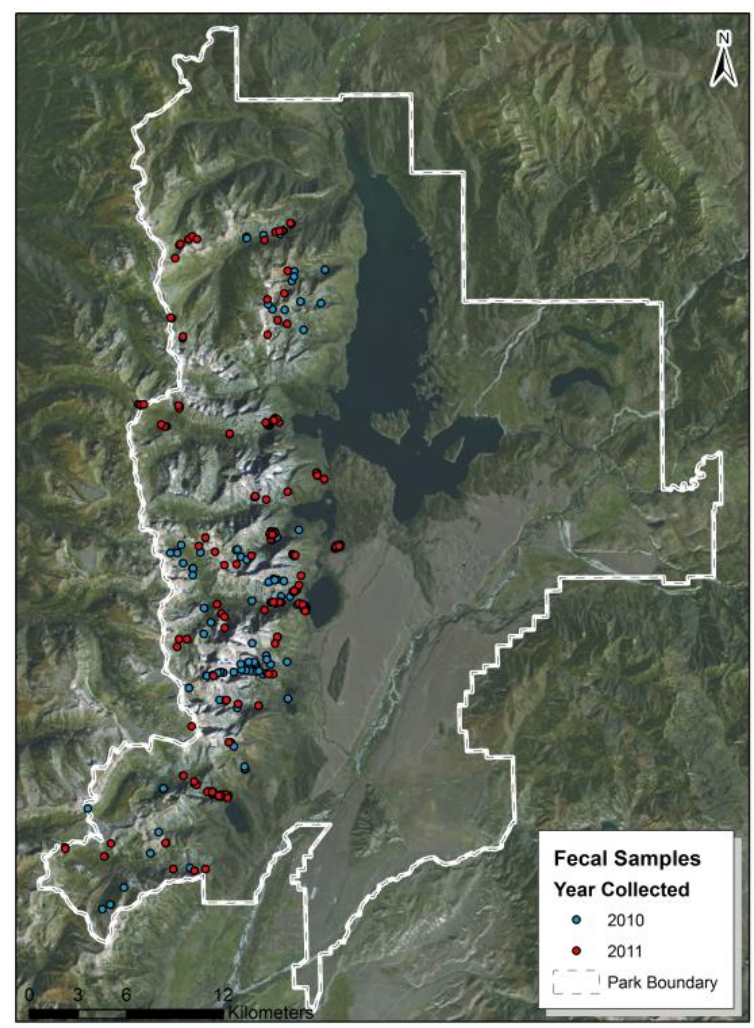

Figure 3. Collection localities of pika fecal samples in Grand Teton National Park for the 2010 and 2011 summer field seasons.

The approximately 200 samples successfully genotyped for all microsatellite markers will be used to characterize genetic diversity and connectivity 
within Grand Teton National Park. Additionally we will develop habitat-specific models of gene flow to understand how distance and intervening habitat affect successful dispersal of pikas. Finally, we will conduct a vulnerability assessment for American pikas based on climate projections and information gained through the predictive habitat models and gene flow models. We will compare among National Parks to gain a more comprehensive understanding of the factors affecting pika persistence.

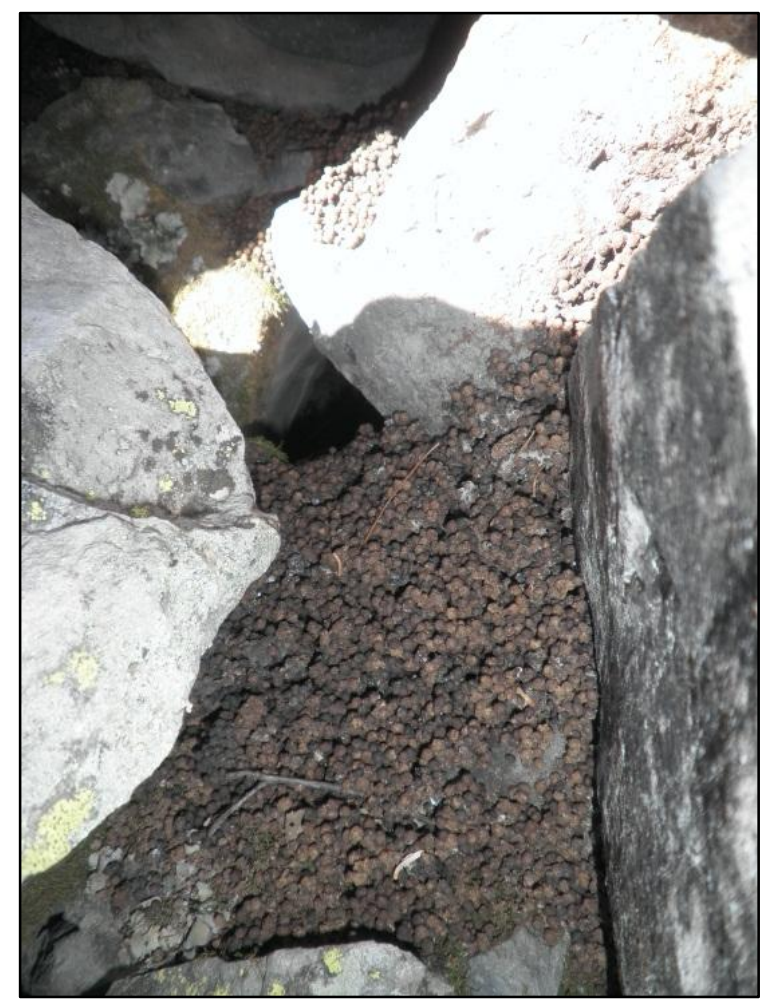

Figure 4. Pika latrine with feces from multiple years and likely multiple individuals.

For additional information on this project, please visit the Pikas in Peril website:

http://science.nature.nps.gov/im/units/ucbn/monitor/p ika/pika_peril/index.cfm

\section{$\uparrow \quad$ ACKNOWLEDGEMENTS}

Funding for this project was provided by the National Park Service Climate Change Response Program. Sue Wolff, Mackenzie Jeffress, Mike Britten, Lisa K. Garrett, and Chris Ray are co-principal investigators on various components of this project. Kerry Gunther, Tom Olliff, Stacey Ostermann-Kelm, Thomas Rodhouse, Billy Schweiger, and Kathi Irvine have contributed greatly to this project as project planners and advisors. Meghan Lonneker and Gordon Dicus coordinated GIS analyses and data management, including creating the Access database. Kathryn Mellander and Ann Rodman provided support by modeling pika habitat and producing essential field maps. Numerous park biologists and field technicians contributed to this project. Additionally, Anne Davis, Clark Peterson, and William Woolen processed samples and conducted lab work.

\section{$\uparrow \quad$ Literature Cited}

Beever EA, Ray C, Mote PW, Wilkening JL. 2010. Testing alternative models of climatemediated extirpations. Ecological Applications 20:164-178.

Beever EA, Ray C, Wilkening JL, Brussard PF, Mote PW. 2011. Contemporary climate change alters the pace and drivers of extinction. Global Change Biology 17:2054-2070.

Beever EA, Brussard PE, Berger J. 2003. Patterns of apparent extirpation among isolated populations of pikas (Ochotona princeps) in the Great Basin. Journal of Mammalogy 84:37-54.

Erb LP, Ray C, Guralnick R. 2011. On the generality of a climate-mediated shift in the distribution of the American pika (Ochotona princeps). Ecology 92:1730-1735.

Hafner DJ. 1993. North-American pika (Ochotona princeps) as a late Quaternary biogeographic indicator species. Quaternary Research 39:373-380.

Hafner DJ. 1994. Pikas and Permafrost: PostWisconsin historical zoogeography of Ochotona in the Southern Rocky Mountains, USA. Arctic and Alpine Research 26:375382.

Jeffress MR, Apel J, Garrett LK, Holm G, Larson D, Nordensten N, Rodhouse TJ. Forthcoming 2013. Upper Columbia Basin Network American pika monitoring protocol. Narrative version 1.0. Natural Resource Report NPS/UCBN/NRR-2010/XXX. National Park Service, Fort Collins, CO.

Krajick K. 2004. Climate change: All downhill from here? Science 303:1600-1602.

McDonald KA, Brown JH. 1992. Using montane mammals to model extinctions due to global change. Conservation Biology 6:409-415. 
Morrison SF, Hik DS. 2007. Demographic analysis of a declining pika Ochotona collaris population: linking survival to broad-scale climate patterns via spring snowmelt patterns. Journal of Animal Ecology 76:899907.
Wehausen JD, Ramey RR, Epps CW. 2004. Experiments in DNA extraction and PCR amplification from bighorn sheep feces: the importance of DNA extraction method. Journal of Heredity 95:503-509. 